\title{
Machado de Assis: um século de traduçóes francesas
}

Machado de Assis: a century of French translations

\author{
Jacqueline Penjon ${ }^{1}$
}

Resumo: Quase um século foi necessário para despertar o interesse do leitor francês por Machado de Assis. 0 estatuto da língua portuguesa, a política editorial, a falta de tradutores, críticos literários e editoras interessadas constituem uma das causas. No entanto, no decorrer do século XX, surgem quatro momentos-chave acompanhando o contexto geopolítico, datas comemorativas, o esforço de mediadores e uma modificação da imagem do Brasil. Destacamos os anos 1910, 1930, 1950 e a década de 80 , em que surge uma nova fase que culmina hoje com a «suíte machadiana», livro de bolso.

Palavras-Chaves: Tradução; mediadores; Machado de Assis; recepção literária.

\begin{abstract}
A century was needed to awake the interest of the French reader by Machado de Assis. The status of the Portuguese language, the editorial politics, and the lack of translators, literary critics and publishing houses are some of the reasons. However, during the $20^{\text {th }}$ century, four key moments arise accompanying the geo-political context, commemorative dates, the efforts of mediators and a change on Brazil's image. We highlight the years 1910, 1930,1950 , and the 80 s, when a new phase is born which culminates today with the «suíte machadiana» pocket book.
\end{abstract}

Keywords: Translation; mediators; Machado de Assis; literary reception.

${ }^{1}$ Sorbonne Nouvelle (Paris 3) - CREPAL. 
La connaissance d'un écrivain étranger est tributaire de l'inégalité linguistico-littéraire.

(Casanova, 1999)

Quando Machado de Assis falece no Rio de Janeiro em 29 de setembro de 1908, sua obra ocupa um lugar de destaque nas letras nacionais, mas na Europa², infelizmente, é completamente desconhecida.

No entanto, o leitor francês já teve oportunidade de ver o nome do autor. O Brasil participou da exposição universal de 1889 em Paris e, para fazer conhecer o país, Frederico José de Santa-Anna Nery organizou Le Brésil en 1889. No capítulo XX, dedicado à literatura e ciências humanas (Nery, 1889: 591-612), Machado de Assis é apresentado como poeta, dramaturgo, tradutor, autor de contos e romances; louva-se a pureza de sua linguagem e a elegância de sua escrita. A seção «Lettres Brésiliennes» do Mercure de France é mais explícita: Machado é considerado por todos como o chefe da literatura brasileira; é perfeito nos contos e, entre os romances, destacam-se Memórias póstumas de Brás Cubas e Quincas Borba. Alberto Figueiredo Pimentel acrescenta que se essas obras fossem traduzidas para o francês ou para outra língua, o sucesso seria retumbante (Pimentel, 1901, 138: 827).

\footnotetext{
2 O Uruguai e a Argentina ganharam traduções quando Machado ainda era vivo: Memorias póstumas de Blas Cubas (Montevidéu, La Razón, 1902) e Esaú y Jacob (Buenos Aires, La Nación, 1905).
}

De fato, poucas seriam as pessoas capazes de ler as obras no original. O português, língua periférica (Casanova, 1999), não consta do sistema educacional francês. Por outra parte, na época de Machado, é o francês que permite uma projeção internacional. Muitos poetas ou escritores escreveram diretamente na língua de Molière. Machado é um deles, contribuiu com uns dez poemas (Massa, 2009). Mas nem por isso deixaram de existir traduções do português para o francês, geralmente por pessoas que viveram nos países lusófonos; mas uma tradução é sempre tributária da existência de uma política editorial, de «passeurs», intermediários, críticos, etc. O próprio Antonio Candido comenta:

Das línguas do Ocidente, a nossa é a menos conhecida, e se os países onde é falada pouco representam hoje, em 1900 representavam muito menos no jogo político. Por isso ficaram marginais dois romancistas que nela escreveram e que são iguais aos maiores que então escreviam: Eça de Queiroz, bem ajustado ao espírito do naturalismo; Machado de Assis, enigmático e bifronte, olhando para o passado e para o futuro, escondendo um mundo estranho e original sob a neutralidade aparente das suas histórias «que todos podiam ler». (Candido, 1995:17)

Machado de Assis queria que suas obras circulassem, portanto que fossem traduzidas. Em carta datada de 10 de junho de 1899 
(Rouanet, 2008, p. 378) pede a seu editor, no caso Hippolyte Garnier³, a autorização de publicar a tradução para o alemão, feita por Alexandrina Highland, o que Ihe foi negado (embora abrisse mão de quaisquer vantagens para si!). A lei de direitos autorais no Brasil é de 1898. A editora Garnier se tornou proprietária da obra literária de Machado em 1899 (Guimarães, 2004: 120). Machado foi persuadido a vender a seu editor os direitos autorais de todas as suas obras, muitas vezes por preço irrisório. Isso impediu por bastante tempo sua difusão no exterior. Philéas Lebesgue, ${ }^{4}$ tradutor de literatura portuguesa, graças a Figueiredo Pimentel, iria traduzir umas obras de Machado. O autor, em carta de 31 de março de 1901, responde a Pimentel que nem pode autorizar uma tradução «porquanto a propriedade das minhas obras está transferida ao Sr. Garnier, de Paris, com todos os respectivos direitos. Só ele poderá resolver sob esse ponto [...]» ${ }^{5}$. Mas deve-se reconhecer

\footnotetext{
${ }^{3}$ Baptiste Louis Garnier (chegou ao Brasil em 1844 abriu uma livraria em 1846 e criou a editora em 1852) fez os contratos para Machado de Assis, o primeiro sendo de 1864 (para Crisálidas) e faleceu em 1893. O herdeiro, o irmão Hippolyte, residia em Paris; cuidou da editora até 1911 (data de seu falecimento) através de um gerente, Julien Lansac, que enviou ao Brasil em 1898. (Hallewell, 2012: 294).

4 Philéas Lebesgue (1869-1958), poeta, erudito autodidata, colaborou regularmente no Mercure de France, para as «Letras Portuguesas» de 1896 a 1940. É tradutor do italiano, do espanhol, do grego moderno e do português.

5 http://www.portalsaofrancisco.com.br/alfa/centenario-de-machado-de-assis/correspondencia-3.php.
}

que Machado ficou cada vez mais prestigiado depois de se ter unido à Casa Garnier. ${ }^{6}$

Foi só a partir de 1913-1910 que Hippolyte Garnier e seus sucessores promoveram as obras de Machado em francês e em espanhol.

\section{Os anos 1910 - 0 «Gênio latino» e «A Festa da intelectualidade brasileira»}

Embora Machado de Assis não fosse lido em francês, sua morte foi noticiada por vários jornais, entre eles, Le Petit Parisien, de 6 de outubro de 1908. O autor é apresentado como Presidente da Academia Brasileira de Letras do Rio e como uma das mais notáveis personalidades da literatura brasileira. Várias obras são mencionadas, entre elas, Memórias póstumas de Brás Cubas; são acompanhadas de um julgamento crítico que insiste na sua fina e discreta ironia e em suas qualidades de observador e psicólogo. Anuncia-se que Rui Barbosa foi designado para ocupar a presidência da Academia. Evidentemente, o Mercure de France de 16-11-1908, na seção «Echos», noticia o falecimento do autor e sublinha que as Memórias póstumas de Brás Cubas o aproximam de Anatole France.

\subsection{O contexto geopolítico}

Na virada do século XIX, impera a ideia de «latinidade»; procura-se estreitar os laços

\footnotetext{
6 Granja, www. circulacaoimpressos.iel.unicamp.br/ index.php ?cd=4\&lang=pt.
} 
de união entre a França e todas as nações latinas do velho e do novo mundo. Em 4 de fevereiro de 1908, é criado o «Groupement des Universités et des grandes écoles de France pour les relations avec l'Amérique latine», à iniciativa de universitários, entre os quais Georges Dumas ${ }^{7}$, para desenvolver as relações intelectuais entre a França e as «Repúblicas irmãs da América Latina». Nasce uma cooperação universitária que não deixa de lado as potencialidades econômicas oferecidas pelos respectivos países, pois a França queria ganhar posições para contrabalançar as ofensivas culturais e econômicas da Inglaterra, da Alemanha, da Itália e dos Estados Unidos. Em 1910, o segundo Presidente do «Goupement», o hispanista Ernest Martinenche, esteve numa longa «tournée» pela América Latina que resultou, no ano seguinte (1911), na criação de um curso de «estudos brasileiros», na Sorbonne, através de uma troca de professores, e de um curso de estudos franceses em São Paulo (1912). Escritores e políticos que viajam pela América Latina não esquecem a etapa brasileira: Anatole France (1909), Georges Clémenceau (1910), Jean Jaurès (1911), Paul Adam, «profeta do espírito latino» convidado pelo ministro das relações exteriores (1911), etc.

\footnotetext{
${ }^{7}$ Georges Dumas (1866-1946) era médico, professor da Universidade de Paris, "agrégé» de filosofia e doutor em Letras; a convite da Sociedade de Psicologia, em 1907, tinha dado uma série de conferências no Brasil.
}

\subsection{A Festa da intelectualidade brasileira}

Em 3 de abril de 1909, no anfiteatro Richelieu, na Sorbonne, foi prestada uma homenagem a Machado de Assis. Essa Festa da intelectualidade brasileira foi promovida por Xavier de Carvalho ${ }^{8}$ e sua «Société des Etudes Portugaises de Paris», com a participação da «Missão Brasileira de Propaganda». Anatole France, da Academia Francesa, que presidia, celebrou «o gênio latino» e seus benéficos efeitos no progresso do velho e do novo mundo. M. de Oliveira Lima, ministro plenipotenciário do Brasil em Bruxelas e acadêmico, pronunciou a conferência «Machado de Assis e sua obra», Victor Orban, vice-cônsul do Brasil em Bruxelas e correspondente estrangeiro da Academia Brasileira, «Machado de Assis romancier, conteur et poète», na qual declara: «C'était un Latin. A cette tradition d'origine, il doit la qualité de son ironie qui est

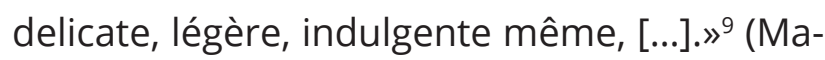
chado, 1909: 96). No livro publicado no final de 1909, retrato fiel da homenagem, estão os textos traduzidos por Victor Orban e lidos na

\footnotetext{
${ }^{8}$ Xavier de Carvalho (1861-1919) poeta e jornalista português, republicano militante, chegou a Paris em 1885; sucedeu a Mariano Pina na redação da Ilustração, etc. Fundou a «Société d'Etudes Portugaises de Paris» em 1902. Em 1909 é redator-chefe da revista Latina, «Revue mensuelle pour la propagande des peuples latins» (19091910). É correspondente de vários jornais portugueses e brasileiros.

9 «Era um Latino. A essa tradição de origem, deve a qualidade de sua ironia, delicada, leve, indulgente até [ ...]».
} 
Sorbonne: o conto «o Enfermeiro», os poemas «Círculo vicioso», «Menina e moça», e «Un vieux pays», escrito em francês por Machado. Em apêndice, estão os depoimentos dados por escritores e personalidades depois do falecimento do autor (Alcindo Guanabara, Ruy Barbosa, Salvador de Mendonça, Euclydes da Cunha, José Veríssimo, Carlos Magalhães de Azevedo). O hebdomadário Les Annales politiques et littéraires reproduz a alocução de Anatole France e o poema «Menina e Moça», traduzido por Victor Orban (11-4-1909).

A partir desse evento, a França conhecerá as primeiras traduções para o francês ${ }^{10}$ de obras de Machado de Assis.

\subsection{Os intermediários -}

\section{Leitores-tradutores}

O ano de 1910 é particularmente importante. Realiza-se em Bruxelas uma exposição internacional em que o Brasil ocupa um lugar privilegiado. ${ }^{11} \mathrm{~A}$ revista Latina $^{12}$ dedica à presença brasileira seu número 11 (10-5-1910), com artigos de Victor Orban (1858-1946). Naquele ano, a tiragem da revista é de 10000 exemplares. O belga Victor Orban Iança pela edi-

\footnotetext{
${ }^{10}$ Não contamos a tradução da fantasia dramática Desencantos, acompanhada de elogioso comentário, publicada em 15-9-1861, no jornal Courrier du Brésil (18541862), órgão da colônia francesa do Rio de Janeiro.

11 Haverá outra em Lisboa, de 15 de outubro de 1910 a 15 de abril de 1911.

${ }^{12}$ Circulou de 10-7-1909 a 20-11-1910. Teve como diretor o Visconde de Faria (até o número 14) e como redator-chefe Xavier de Carvalho.
}

tora Garnier a primeira antologia metódica da literatura brasileira em francês, prefaciada por M. de Oliveira Lima. Terá logo uma segunda edição. No verbete Machado de Assis, Orban acrescentara às traduções já lidas o último parágrafo do capítulo XXIV de Memórias póstumas de Brás Cubas e o poema «Uma criatura». Um segundo «passeur», Adrien Delpech (1867-1942) ${ }^{13}$, professor e escritor que morava no Rio de Janeiro, foi o primeiro tradutor de um livro inteiro, os contos de Várias histórias (1896), publicados pela editora Garnier com o título Quelques contes. No prefácio, explica seu conceito de tradução: «J'ai traduit Machado de Assis, c'est-à-dire que j'ai superposé à sa mentalité une autre mentalité bienveillante et aussi harmonique que possible avec la sienne» ${ }^{14}$ (Assis, 1910: XXVII). No ano seguinte, publica pela mesma editora Mémoires posthumes de Bras Cubas. O prefácio a Quelques contes deixava entender que comprendera razoavelmente bem o estilo machadiano, mas para o romance, Delpech se comportou como o avesso do «leitor modelo» definido por Umberto Eco. Daremos apenas um exemplo: eliminou pura e simplesmente o capítulo cxXX

\footnotetext{
13 Depois de estudos em Paris, Adrien Delpech emigrou para o Brasil, onde se naturalizou em 1891. Professor de francês e de sociologia, de literatura brasileira e latina no D. Pedro II, na Escola Normal, etc., publicou romances em francês: Roman brésilien, mœurs exotiques (1904), Pages exotiques: Petrópolis (1913), L'ldole (2. a ed. 1930).

14 «Traduzi Machado de Assis, quer dizer, superpus a sua mentalidade outra mentalidade benévola e a mais harmônica possível com a sua».
} 
intitulado «Para intercalar no capítulo CXXIX» já que, ao pé da letra, incorporou o conteúdo ao capítulo CXXIX. A obra ficou amputada de um capítulo! Omitiu também a dedicatória ao verme e o prólogo assinado «Machado de Assis», presente desde a quarta edição (1899). Na opinião de Raimundo Magalhães Jr.: «Foi assim que, três anos após a morte de Machado de Assis, os irmãos Garnier the «honraram» a memória, com a divulgação, em mau francês, do maior dos seus romances...» (Correio da Manhã, 26 de outubro de 1957: 9). Datada também de $1911,{ }^{15}$ a edição espanhola, Memorias postumas de Blas Cubas, na tradução de Rafael Mesa López (Paris, Garnier Hermanos), mostra-se perfeitamente fiel ao original.

Alguns contos são publicados como folhetins pelo semanal Courrier du Brésil/16, de dezembro de 1910 a novembro de 1911. Inspiram várias retraduções. Por exemplo, «O enfermeiro», traduzido por Orban em 1909 e por Delpech em 1910, é retraduzido em 1911, a quatro mãos, por Philéas Lebesgue e Manoel Gahisto, que o publicam na revista Les Mille Nouvelles Nouvelles ${ }^{17}$. O escritor Henri Allorge, que

\footnotetext{
15 Pelo mesmo tradutor, sai também, em 1911, Varias historias.

${ }^{16}$ Este Courrier du Brésil foi criado em 1906, em Paris, por M. Medeiros e Albuquerque para leitores franceses e brasileiros; no ano seguinte, passa sob a direção de Mendes de Almeida Jr., proprietário do Jornal do Brasil e da Revista semanal.

17 Les Mille nouvelles nouvelles, revue mensuelle pour tous, 1910-1912. Philéas Lebesgue (1869-1958) colaborou
}

assina a coluna «Notes de littérature brésilienne» na revista Le Penseur (t. 11, janeiro de 1911), aproveita a antologia de Orban para ilustrar com «Un Vieux Pays» a parte dedicada a Machado de Assis. Benedicto Costa, no capítulo IV dedicado a Machado no livro Le roman au Brésil (1918), lançado em Paris, escolhe as traduções de Delpech: o conto «Viver»e o capítulo VII, «O Delírio», das Memórias póstumas. Mas, como declara preferir Dom Casmurro, traduz o capítulo IV do romance, «Um dever amaríssimo». Para o centenário da independência, a Revue de l'Amérique latine18 faz uma homenagem ao Brasil. Lebesgue colabora com a tradução de «A mosca azul» (Revue Amérique latine, 1-9-1922). Orban publica outra antologia, La poésie brésilienne, na Garnier (1922) ${ }^{19}$. Retoma os poemas que traduzira em 1909 e 1910 e acrescenta apenas «A Carolina». Uma vez ou outra, aparece mais um conto, por exemplo, «Pai contra mãe»,

mais de 45 anos no Mercure de France (letras portuguesas e brasileiras). Traduz Alencar e Machado de Assis. Pierre-Manoel Gahisto (1878-1948), belga, pseudônimo de Paul Tristan Coolen, traduz também Aluízio Azevedo.

${ }^{18}$ A Revue de l'Amérique Latine (1922-1932) teve como diretor Ernest Martinenche.

${ }^{19}$ Victor Orban dedica o livro a Xavier de Carvalho: «Ce livre, véritable profession de foi devait être dédié à Xavier de Carvalho, fondateur de la Société des Etudes Portugaises. Le compagnon enthousiaste de mes luttes mort à Paris le 2 août 1919». O prefácio é do primeiro secretário da Embaixada do Brasil, Mário de Pimentel Brandão. 
traduzido por Jean Duriau (1887-1936) ${ }^{20}$, em 1926, na Revue de l'Amérique Latine,

Afinal, essas traduções têm pouca repercussão. O jornal Le Temps (6-11-1910) anuncia as resenhas de duas obras: "Chanaan de J. Graça Aranha, da Academia Brasileira, traduzido por Clément Gazet, prefácio do conde Prozor, Paris, Plon. Quelques contes por Machado de Assis, traduzidos por Adrien Delpech, Paris, Garnier». Vê-se a preferência pelo primeiro livro já no anúncio. A resenha, assinada «Gaston Deschamps», apresenta Graça Aranha como diplomata muito parisiense, letrado de cultura europeia e francesa. Muito detalhada, ela ocupa todo o espaço e o autor declara que falará na próxima vez (o que não aconteceu) dos contos de Machado de Assis, o Mérimée do Rio. Anuncia que, durante $\mathrm{o}$ ano, M. Oliveira Lima ministrará um curso na Sorbonne sobre sua obra. ${ }^{21}$ O Le Temps, jornal republicano conservador, tornara-se órgão oficioso da diplomacia francesa, o que pode explicar esse descaso.

O escritor Henri Pourrat, em carta (16-3-1918) a seu amigo Joseph Desaymard, qualifica as

\footnotetext{
20 Jean Duriau abandonou os estudos de medicina. Em 1912, é responsável pela Companhia Chargeurs Réunis em Santos. Volta à França durante a guerra mas retorna ao Brasil de 1919 a 1922. Traduz obras brasileiras e colabora na Revue de l'Amérique Latine.

${ }^{21} \mathrm{M}$. de Oliveira Lima só tratou de literatura na homenagem a Machado de Assis em 1908. O ciclo de conferências programado para 1911 intitula-se: «Formation historique de la nationalité brésilienne».
}

Mémoires posthumes, que está lendo, de livro de humor bastante fraco!! (Pourrat, 2013: 269).

Em resumo, se Machado é comparado a Anatole France, ou assimilado a Mérimée, muitos censuram sua falta de pitoresco, de descrições, de «paisagens»: Delpech (Assis, 1910) e Lebesgue (Mercure de France 16-2-1910). Vale lembrar que a partir de 1896, foram oferecidos aos leitores franceses livros com visão impressionista da natureza (Alencar, Taunay, Coelho Neto, A. Peixoto). Os contatos culturais entre a França e o Brasil eram feitos através da oligarquia brasileira, que ajudava na escolha das obras a serem traduzidas, obras que valorizavam a natureza tropical, a aventura, a fortuna, como é o caso de Le fils du soleil, tradução de O Guarani por Xavier de Ricard (Ed. de Jules Tallandier, 1902), o livrinho de Afonso Celso, Porque me ufano do meu país, traduzido pela condessa de Serra negra, Pourquoi je m'enorgueillis de mon pays, editado pela Garnier em 1912 com fotografias que, aliás, não constam da edição brasileira, etc. Segundo Manoel Gahisto, o público leitor apreciaria sobretudo as descrições de paisagens, as evocações da luta sempre ardente contra as forças esmagadoras da natureza tropical, os «efeitos do pitoresco», mesclados às «emoções dos espetáculos grandiosos do deserto» (Boisvert, 1991).

Identidade latina e falta de aliança com a natureza, foram mais dois obstáculos ao reconhecimento do autor. 


\section{Os anos 30 - Em torno do centenário do nascimento do autor}

Na década de 1930, aumenta a cooperação entre a França e o Brasil e a troca de professores com a criação da Universidade de São Paulo em 1934 e a Universidade do Brasil, no Rio de Janeiro, em 1935. Jean Duriau procura modificar a imagem de Machado e sublinha que

L'homme de ses romans n'est pas spécialement un Brésilien, mais un homme, et cela seul suffirait à justifier notre profonde admiration pour l'auteur de tant de livres inconnus en France; ils perdraient, du reste, tout leur charme à être traduits: ils sont, en effet, écrits d'une manière qui défie l'interprétation, en raison même de son élégance et de sa subtilité. ${ }^{22}$ (Revue Amérique Latine, 1932, 123: 239).

Refere-se, certamente, às Memórias póstumas traduzidas por Delpech.

O ano de 1939 marca o centenário do nascimento do autor; o Instituto Internacional de Cooperação Intelectual23, na Coleção

22 «O homem nos seus romances não é o brasileiro, mas sim o homem universal, o que justificaria nossa admiração pelo autor de tantos livros desconhecidos na França; perderiam, aliás, seu encanto se fossem traduzidos, pois a escrita desafia a interpretação pela elegância e sutileza».

${ }^{23}$ Órgão da Sociedade das Nações (SDN), a «Comissão internacional de cooperação intelectual», criada em 1922, transforma-se em «Instituto Internacional de Cooperação Intelectual» em 1926, com sede em Paris. Ser-
Ibero-Americana, lança, em 1936, Dom Casmurro, traduzido por Francis de Miomandre ${ }^{24}$. Afrânio Peixoto, que assina o prefácio, declara: «Quand la traduction est d'un écrivain distingué, quand l'éditeur est la Société des Nations, c'est grande gloire pour Machado de Assis» ${ }^{25}$ (Assis, 1936: 8-9); mas neste prefácio desenvolve também a estranha ideia de que é por ser gago que escreve com frases curtas e recortadas! A nova tradução é apresentada nas revistas especializadas. René Lalou nota que Machado de Assis se aproxima de Sterne pelo humor e de Jules Renard pela «finesse et sobriété du trait» ${ }^{26}$ (Les Nouvelles Littéraires, 199-1936). André Rousseaux, do Figaro littéraire (17-10-1936), muito condescendente, qualifica o romance de «gentil», a tradução de «charmante». Para Maurice Muret, crítico suíço do Journal des Débats (13-1-1937), «le mérite du livre réside tout entier dans la façon dont il est présenté» ${ }^{27}$. Todos os críticos da época deixam entender que Bentinho pertence ao clube dos maridos enganados. Manoel Gahisto, no Mer-

virá de base à criação da UNESCO, em 16 de novembro de 1945 (Londres).

${ }^{24}$ Francis de Miomandre é o nome literário de Francis Durand (1880-1959); escritor e tradutor, recebe o prêmio Goncourt em 1908, com o livro Écrit sur l'eau. Traduz do espanhol (Cervantes, Calderón, etc. e do português). Colabora em várias revistas: Nouvelles Littéraires, Cahiers du Sud.

25 «Quando a tradução é de um escritor distinto, quando o editor é a Société des Nations, é uma grande glória para Machado de Assis».

26 «fineza e sobriedade do traço».

27 «o mérito todo do livro está na maneira como é apresentado». 
cure de France (janeiro de 1937), na crônica dedicada à tradução de Dom Casmurro, insiste sobre o humor, mas ainda repete que não há nenhuma descrição de paisagem.

A Academia Brasileira de Letras lança, em 1938, uma Anthologie de quelques conteurs brésiliens (31 autores). As traduções são do acadêmico Luiz Aníbal Falcão. Machado é representado pelo conto «Um Apólogo», o que deixou Mário de Andrade muito perplexo:

De Machado de Assis apenas duas páginas, o fraco apólogo da agulha e da linha, que ficou muito sem pouco, vertido para o francês, uma pena. Eu não sei quais são as normas de discrição em uso na Academia, mas não pude compreender exatamente as intenções dos organizadores do volume, se dando farto abrigo no livro e a Machado de Assis apenas duas páginas de letra de forma. Naturalmente terão pensado que a recente tradução de Dom Casmurro compensava a quase omissão.» (Andrade, 1972: 37).

Para o centenário de Machado, Le Temps (23-7-1939) publica uma nota, na qual o Presidente da Academia, Antonio Austregésilo, declara: «Machado de Assis mériterait d'être mieux connu à l'étranger ${ }^{28}$.

28 «Machado de Assis mereceria ser mais conhecido no estrangeiro».

\subsection{Roger Bastide mediador cultural}

O melhor leitor de Machado de Assis foi o sociólogo Roger Bastide, que chegou ao Brasil em 1938 para lecionar na recém criada Universidade de São Paulo ${ }^{29}$. Um ano depois, para o centenário do nascimento do autor, exprime seu prazer de leitor ao descobrir Dom Casmurro na excelente tradução de Miomandre e pede ao Instituto Internacional de Cooperação Intelectual o favor de «faire connaître du public français au moins cet étrange Brás Cubas qui fait de Machado de Assis l'original devancier d'un Proust ou d'un Pirandello» ${ }^{30}$ (Bastide, 1939: 18). Em 1940, publica na Revista do Brasil um artigo decisivo, contrariando a opinião da maioria dos críticos: «Machado de Assis paisagista». Escreve: «a natureza, nele [Machado], não é ausente, mas ele soube imprimir o intervalo que a separava das personagens, misturando-a com estas, fazendo-a colar-se-lhe à carne e à sensibilidade, integrando-a na massa com que constrói os heróis de seus romances» (Revista do Brasil, 1940: 9). Mostra que

\footnotetext{
${ }^{29}$ A USP foi criada pelo decreto de 25-1-1934; a cátedra de sociologia foi ocupada por P. Arbousse-Bastide, aluno de G. Dumas; desdobrada em 1935, chegou na outra cátedra Claude Levi-Strauss que voltou à França em 1938. Foi substituído, então, por Roger Bastide (1898-1974) que viveu no Brasil entre 1938 e 1954.

30 «fazer conhecer ao público francês o estranho Brás Cubas que transforma Machado em original antecessor de um Proust ou de um Pirandello».
} 
o que caracteriza a natureza carioca são a vegetação sensual, as voluptuosas noites quentes de verão, e sobretudo a presença do mar. Ora, esses três elementos são transpostos para se tornarem carne, sangue e vida, para integrar a arquitetura da face, para correr nas veias e bater docemente no pulso, sob a delicadeza de uma pele feminina. As laranjeiras perfumadas das chácaras, os recantos de sombra úmida sob as árvores, a vida vegetal dos trópicos, que talvez não descreva, inscrevem-se no andar dessas mulheres-vegetais, dessas mulheres-paisagens. As noites do Rio se tornam cabeleiras, cabelos soltos, perfumados, mornos, voluptuosos, «cortados da capa da última noite». [...] os olhos das heroínas de Machado de Assis, olhos verdes, olhos de ressaca, olhos de escuma com reflexos irisados, são feitos da própria cor do oceano que banha as praias do Brasil, guardando em suas vagas o encanto de lemanjá, o apelo dos abismos, a carícia e a traição. (Revista do Brasil, 1940: 10).

O leitor francês terá acesso às novas interpretações da obra machadiana no Mercure de France, quando Bastide sucede a Lebesgue em 1949.

Bastide foi um verdadeiro «passeur». Alegra-se muito num artigo do Estado de São Paulo (26-8-1944) quando sai pela editora Atlântica do Rio ${ }^{31}$, na coleção «les maîtres des

31 A ocupação da França (1940-1944) provocou a emigração de muitos intelectuais e a implantação de edi- littératures américaines», a tradução Mémoires d'outre-tombe de Bras Cubas, pelo General René Chadebec de Lavalade, prefaciado por Afrânio Peixoto. Bastide sublinha a dificuldade da tradução e reconhece que o francês conserva o encanto do original.

René Chadebec de Lavalade (1881-1967), leitor muito especial, foi o último chefe da Missão militar (1938-1940) que a França, desde 1919, mantinha no Brasil; é autor, também, de um requisitório contra Pétain. Afrânio Peixoto, num pequeno prefácio, louva a cultura e as qualidades do tradutor, sublinha que o General «a su incorporer de façon définitive à sa langue une œuvre qui le méritait et qu'il a réussi à traduire, à exprimer, avec autant de limpidité que de profonde exactitude» ${ }^{32}$ (Assis, 1944: 9). A tradução passou meio desapercebida em Paris, o período não era muito propício! Uma pequena editora parisiense, Emile-Paul Frères, fez outra tiragem em 1948; acrescentou um estudo sobre Machado assinado pelo acadêmico André Maurois.

\section{0 interesse pela América Latina}

A América Latina ganha notoriedade na década de 50. A pedido do ministério dos Negócios estrangeiros, foi criada em Paris a Maison

toras fora do país. Charles Ofaire, editor suiço instalado no Rio, dirigia a Atlântica Editora, ao mesmo tempo que militava pelo combate pela França livre.

32 «soube incorporar de modo definitivo e sua língua uma obra que o merecia, obra que conseguiu traduzir, exprimir de maneira límpida e profundamente exata». 
de l'Amérique Latine em 1945. Em 1954, nasce o Institut des Hautes Etudes de l'Amérique Latine (IHEAL), com Pierre Monbeig como diretor. Cresce o interesse pelo Brasil. Vários autores são traduzidos, Jorge Amado ${ }^{33}$, Euclides da Cunha, José Lins do Rego, Érico Veríssimo, etc. O leitor francês continua apreciando exotismo, imagens tropicais, carnaval e samba.

Em 1958, comemoram-se os 50 anos da morte de Machado de Assis. Com a ajuda da UNESCO, a editora Nagel lança, em 1955, Quincas Borba, traduzido por Alain de Acevedo e com prefácio de Roger Bastide. Um ano depois, Albin Michel lança nova publicação de Dom Casmurro, na tradução de Miomandre, com uma nota que associa, para a revisão, Ronald de Carvalho (falecido num acidente).

Nas duas décadas seguintes, os centros de interesses tornam-se mais sociais com Josué de Castro, Celso Furtado, D. Hélder Câmara, etc.

\subsection{Machado de Assis no círculo acadêmico}

A primeira tese de doutorado defendida sobre a obra de Machado de Assis, da autoria de Jean-Michel Massa, «La jeunesse de Machado de Assis (1839-1870) — essai de biographie intellectuelle», na Universidade de

33 Em 1938, saiu pela Gallimard a tradução de Jubiabá, por Michel Berveiller e Pierre Hourcade, que estiveram na USP pelo acordo de cooperação. O livro fez muito sucesso e, segundo Roger Bastide, pôs em voga a literatura brasileira na França (O Estado de São Paulo, 26-8-1944).
Poitiers, em 1969, dá um novo impulso aos estudos machadianos. Pouco depois, Memórias póstumas de Brás Cubas integra os primeiros programas de concursos para professores de português em colégios e liceus, língua que acabava de entrar no sistema educacional.

Em 1976, Roberto Schwarz (em Paris na época) defende, em Paris3, com o Professeur Raymond Cantel, a tese «Forme littéraire et processus social aux débuts du roman brésilien», que no ano seguinte dará lugar ao livro Ao vencedor as batatas. Deste mesmo ano é a tese de $3 .^{\circ}$ ciclo de Pierre Rivas (em Literatura Comparada), sob a direção do Professor Pierre Brunel, em Paris4, «Les relations littéraires entre la France, le Portugal et le Brésil (1880-1930)», que evoca Machado de Assis sob o ângulo da latinidade. Multiplicam-se os doutorados (Literatura Brasileira ou Literatura Comparada) e os mestrados sobre a obra machadiana.

Mas, entre 1978-1980, uma pesquisa de opinião revela que só $1 \%$ do grande público conhece ou ouviu falar de Machado de Assis, contra 8\% para Jorge Amado, 3\% para João Guimarães Rosa (Fresco, 1981).

\section{A década de 80 - Uma editora dedicada: Anne-Marie Métailié}

Mudou a política editorial. As editoras escolhem as obras que querem publicar. Recebem ajudas de diferentes organismos para as traduções: Centro Nacional do Livro (CNL), Unesco. Vários 
eventos literários concorrem à promoção das literaturas: em 1987, as «Belles étrangères», em 1998 e 2015, o Brasil como convidado de honra do Salão do Livro, em 2005, o ano do Brasil na França, e sempre os festivais «Étonnants voyageurs» de Saint Malo, «Belles lae tinas» de Lyon, a ADELC (Association pour le Développement de la Librairie de Création), rede de livrarias apoiada pelo ministério da Cultura e pelos editores, etc.

Nesse novo contexto, a editora Métailié foi fundada em 1979; exibe como emblema uma salamandra, símbolo da paixão (sendo seu lema «Des livres pour vivre passionnément $\left.{ }^{34}\right)$. Anne-Marie Métailié é formada em letras, espanhol-português. Teve como professores Georges Boisvert e Antonio Candido (professor convidado na Sorbonne em 1965). Diz ela que foi decisivo: «tinha descoberto uma língua com a qual me dava bem, eu sentia a música dessa língua». Com interesse maior para a América Latina, começou publicando obras de Ciências Humanas; pouco depois, lançou-se na publicação de textos literários. O primeiro autor foi Machado de Assis, o que corresponde a um projeto pessoal. Nas aulas com o Prof. Boisvert, em 1963, estudou Dom Casmurro; apaixonada, no final do ano letivo ela podia decorar capítulos inteiros! Mas ao lê-lo em francês, notou que faltava a ironia, o que tirava o essencial. Empenhou-se em

\footnotetext{
34 «Livros para viver com paixão».
}

fazer ler o que ela lia em português. ${ }^{35}$ Lançou uma nova tradução de Dom Casmurro (1983), feita por Anne-Marie Quint; foi bem acolhida, os artigos na imprensa foram positivos, por exemplo, a Quinzaine Littéraire (19/31 de março de 1983) apresenta o olhar perfeito da leitora «Machado de Rio» assinado por Clélia Piza. No entanto, alguns críticos ainda mostraram suas lacunas, fazendo de Machado um escritor de Minas Gerais aberto ao Rio industrial e à aridez dos Campos Gerais (Magazine Littéraire - março de 1983).

Aos poucos são traduzidos e publicados: Esaü et Jacob, tradução de Françoise Duprat, 1985; Ce que les hommes appellent amour [Memorial de Aires], tradução de Jean-Paul Bruyas, 1985; Mémoires posthumes de Brás Cubas, tradução de Chadebec de Lavalade, 1989 (A.M. Métailié republica a tradução de 1944 com pequenas modificações, por exemplo, no título - abandona «outre-tombe» que lembrava que Chateaubriand fora um dos autores de predileção de Machado de Assis -, mas a dedicatória ao verme e o prefácio de Machado de Assis continuam ausentes); Quincas Borba, tradução de Jean-Paul Bruyas, 1990; La Montre en or (contos), tradução de Maryvonne Lapouge-Pettorelli, 1998; La théorie du médaillon (contos e crônicas), tradução de Florent Kohler, 2002.

\footnotetext{
${ }^{35}$ Os detalhes foram dados por A.M. Métailié numa troca de correspondência.
} 
Os tradutores são quase todos professores universitários. Os prefácios são sempre escritos por especialistas. Em 1984, O Alienista, traduzido por Maryvonne Lapouge-Pettorelli é prefaciado pelo comparatista Pierre Brunel; os contos de La montre en or são precedidos da conferência de Antonio Candido, «Machado de Assis: schéma» (1968), publicada em 1970, em Vários Escritos, etc.

O público vai crescendo e se diversificando: universitários, professores de línguas estrangeiras, leitores comuns que frequentam os eventos literários e os lançamentos em livrarias. Com o decorrer dos anos, os críticos eliminaram os clichês deformantes. Os artigos ligados a Machado para o Salão do Livro de 2015 o comprovam.

Anne-Marie Métailié criou, em 1997, uma coleção de semi-bolso «suite brésilienne» [formato mais moderno e mais barato] e, para o Salão de 2015, a «suite machadiana», que conta mais de sete volumes. Ela não tem a exclusividade de Machado. Outras editoras publicam contos, uma vez ou outra, como Ombre em Toulouse, Chandeigne em Paris ou Garnier (Histoires diverses, 2015, na tradução de Saulo Neiva), etc.

Machado é agora citado ou utilizado em obras de teoria literária. Brás Cubas ilustra o capítulo sobre o prefácio fictício no estudo de Gérard Genette sobre o peritexto; cita um longo trecho do prefácio de Brás Cubas que, como autor, anuncia uma obra difusa (Genette, 1987: 193, 294). Refere-se várias vezes ao autor, a saudosa Pascale Casanova, em La république mondiale des lettres (1999). Tiphaine Samoyault vale-se de dois contos machadianos, «o relógio de ouro»e «o espelho, esboço de uma nova teoria da alma humana» no seu livro, reflexão teórica e estética sobre o tempo, seus desregulamentos e nossa relação com a temporalidade (Samoyault, 2004). Está presente até em livro de divulgação, o «Petit Mercure», coleção para grande público de textos literários, no volume sobre o chá, que convoca o capítulo 115 de Dom Casmurro (Astier, 2007). Em conclusão, podemos dizer que é graças ao trabalho e ao empenho de Anne-Marie Métailié que Machado de Assis é hoje lido e reconhecido como um dos maiores escritores brasileiros.

\section{Bibliografia}

Academia Brasileira de Letras (1938). Anthologie de quelques conteurs brésiliens. Sagittaire. Paris;

Andrade, M. (1972). Feitos em França. Em: O Empalhador de Passarinho. Martins. São Paulo; Assis, J.M.M. (1910). Quelques contes. Garnier. Paris;

Assis, J.M.M. (1911). Mémoires posthumes de Brás Cubas. Garnier. Paris;

Assis, J.M.M. (1936). Dom Casmurro. Institut International de Coopération Intellectuelle, «Collection Ibéro-américaine». Paris;

Assis, J.M. Machado de, (1944). Mémoires d'outre-tombe de Brás Cubas. Atlântica Editora. Rio de Janeiro; 
Assis, J.M. Machado de, (1948). Mémoires d'outre-tombe de Brás Cubas. Editions EmilePaul Frères. Paris;

Assis, J.M. Machado de, (1998). La Montre en or. A.M. Métailié. Paris;

Assis, J.M. Machado de, Correspondência com Figueiredo Pimentel. Acedido em 26 de julho de 2018, em: http://www.portalsaofranp cisco.com.br/alfa/centenario-de-machado-de-assis/correspondencia-3.php.

Astier, I. (2007). Le goût du thé. Mercure de France. Paris;

Bastide, R. (1939, 20 de maio). Hommage. Em: Dom Casmurro, 101-102: 18;

Bastide, R. (1940). Machado de Assis paisagista. Em: Revista do Brasil, 29(3): 1-14;

Bastide, Roger, (1944, 26 de agosto). Em torno de uma tradução de Memórias póstumas de Brás Cubas. Em: O Estado de São Paulo;

Boisvert, G. (1991). A imagem do Brasil na França através das traduções. Em: S. Parvaux e J. Revel-Mouroz. Imagens recíprocas do Brasil e da França. IHEAL. Paris. pp. 615-617;

Candido, A. (1995). Esquema de Machado de Assis. Em : Vários Escritos. Duas Cidades. São Paulo. pp.13-32;

Casanova, P. (1999). La République mondiale des lettres. Editions du Seuil. Paris;

Costa, B. (1918). Le roman au Brésil. Garnier. Paris;

Eco, U. (1985). Lector in fabula: le rôle du lecteur ou la coopération interprétative dans les textes narratifs. Librairie générale française. Paris;

Fresco, D. (1981). La culture brésilienne vue par le public français d'aujourd'hui. Tese de $3 .^{\circ}$ ciclo (exemplar datilografado). Universidade de Paris 3 - Sorbonne Nouvelle. Paris;
Genette, G. (1987). Seuils. Editions du Seuil. Paris;

Granja, L. (s.d.) Fontes para o estudo da edição no Brasil: os contratos e recibos da editora B.L.Garnier. Acedido em 27 de julho de 2018, em: www. circulacaodosimpressos.iel.unicamp.br/index.php?cd=4\&lang=pt;

Guimarães, Hélio de Seixas, (2004). Os Leitores de Machado de Assis: o romance machadiano e o público de literatura no século XIX. Nankin/ Edusp. São Paulo;

Hallewell, L. (2012). O Livro no Brasil: sua história. (3. ${ }^{a}$ ed.). Edusp. São Paulo;

Machado de Assis et son oeuvre littéraire. (1909). Louis-Michaud Editeur. Paris;

Massa, J.M. (2009). A França que nos legou Machado de Assis. Em B. Antunes e S.V. Motta (orgs.), Machado de Assis e a crítica internacional. Ed. Unesp. São Paulo. pp. 231-265;

Magalhães Jr., R. (1957, 27 de outubro). Duas traduções francesas de um romance de Machado de Assis. Em: Correio da Manhã. Rio de Janeiro. p. 9;

Nery, F.-J. Santa-Anna (org.) (1889). Le Brésil en 1889. Delagrave. Paris;

Pimentel, A.F. (1901, junho). Lettres Brésiliennes. Mercure de France, 138;

Pimentel, A.F. (1902, maio). Lettres Brésiliennes. Mercure de France, 149;

Pourrat, H. (2013). Correspondance croisée Henri Pourrat- Joseph Desaymard d'octobre 1913 à 1918: la Grande Guerre. Em: https://gallica.bnf.fr/ark:/12148/bpt6k97628810;

Rouanet, S., et al. (2008). Correspondência de Machado de Assis. Academia Brasileira de Letras. Rio de Janeiro. T. 3 (1890-1900);

Samoyault, T. (2004). La montre cassée. Verdier. Paris. 